\title{
Life Cycle Assessment of the wind farm alpha ventus
}

\author{
H.-J. WAGNeR $\left(^{*}\right)$ \\ Energy Systems and Energy Economics, Ruhr-University Bochum \\ P.O. Box 102148, 44721 Bochum, Germany
}

\begin{abstract}
Summary. - Life Cycle Assessments (LCA) is an important tool for industry and policy makers, used to determine the actual emissions of a product or technology throughout its whole life cycle. In case of energy production systems or power plants, analysis of energy required to produce the materials and processes; emissions resulting from various processes for materials production and processes resulting into their Cumulated Energy Demand (CED) and Global Warming Potential (GWP) become important parameters when making decisions on further research, development and deployment of any technology. The method of carrying out such analysis is explained through a case study.
\end{abstract}

\section{1. - Basic targets and approach}

The four different steps of a life cycle assessment are defined in the international standards DIN EN ISO 14040 [1] and DIN EN ISO 14044 [2]:

The Goal and scope definition includes the description of the balance object, the system boundaries and the assumptions made.

$\left(^{*}\right)$ E-mail: lee@lee.rub.de

This is an Open Access article distributed under the terms of the Creative Commons Attribution License 2.0, which permits unrestricted use, distribution, and reproduction in any medium, provided the original work is properly cited. 
During the Inventory analysis all material, energy and emission flows (input and outputs) are investigated and lead to the life cycle inventory analysis result.

Within the Impact assessment, the impact categories as well as their indicators are defined. The inputs and outputs are classified by these impact categories. Using characterization factors, the impact category indicators are calculated.

Finally, in the Interpretation step, the results of the life cycle assessment are evaluated to reach conclusions. Additionally, an optional sensitivity analysis can investigate responsive parameters and their influence on the results.

Three different methodological approaches exist to calculate the above-mentioned indicators:

- the energetic input output analysis,

- the process chain analysis and

- the material balance analysis.

When using the input output analysis, there is a high possibility of receiving inaccurate results. A process chain analysis depends on detailed process data and is an extremely time consuming balancing process. A good compromise between a high accuracy of the result and an acceptable expenditure of time can be reached by a material balance analysis. Another advantage is that data concerning mass, material and type of production are sufficient to calculate the indicators.

\section{2. - Case study of alpha ventus}

Results and characteristics of wind energy LCA can be best described using an example. Therefore in the following chapters the carried out LCA of the offshore wind farm alpha ventus will show the different steps and important conclusions of results of LCA of a wind energy system.

2'1. Goal and scope definition. - The object of investigation is the first German offshore wind farm alpha ventus beyond the territorial waters (twelve mile zone) in the German exclusive economic zone. Alpha ventus is a test field in the North Sea for $5 \mathrm{MW}$ wind energy converters in a water depth of $30 \mathrm{~m}$ (fig. 1). The field consists of six converters of the type 5M (manufacturer REpower) that are installed on Tripod foundations and six converters of the type M5000 (manufacturer Multibrid) that are built on Jacket foundations (fig. 2). All converters are connected by a $16 \mathrm{~km}$ submarine cable at $30 \mathrm{kV}$. An offshore transformer station steps up the voltage for the $110 \mathrm{kV}$ submarine cable. The electricity is transported over $60 \mathrm{~km}$ to an onshore transformer station, which supplies the German high-voltage grid. Several indicators are taken into consideration and investigate the resource conserving and environmentally friendly way of power generation in comparison to the German grid mix. The functional unit was defined as the supply with $1 \mathrm{kWh}$ current generated by alpha ventus at the high-voltage grid at the onshore transformer station at the coast. 


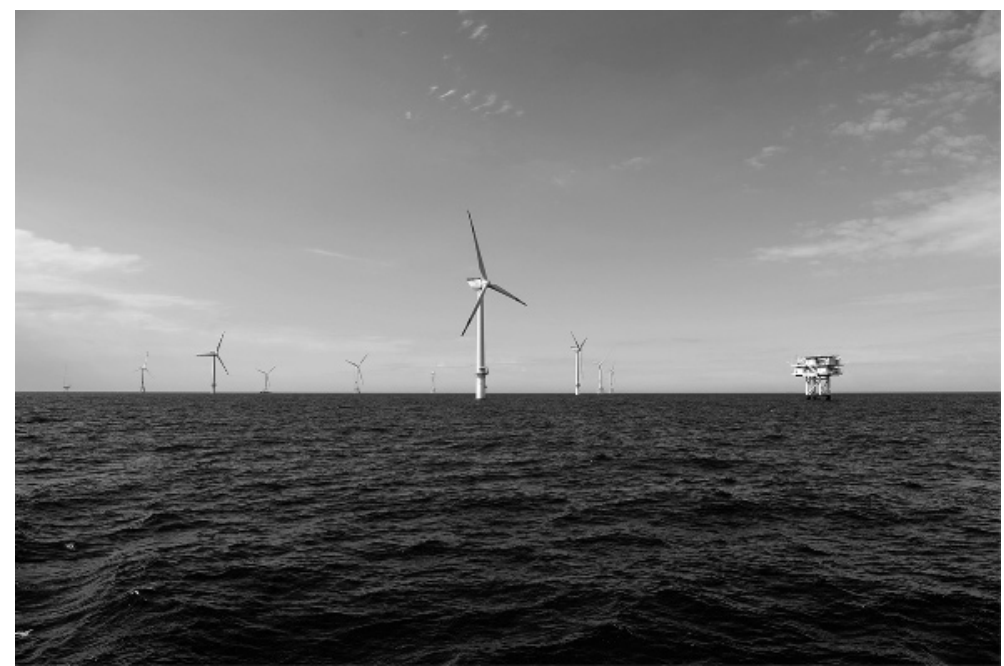

Fig. 1. - Wind farm alpha ventus (photo: (C) DOTI 2009).

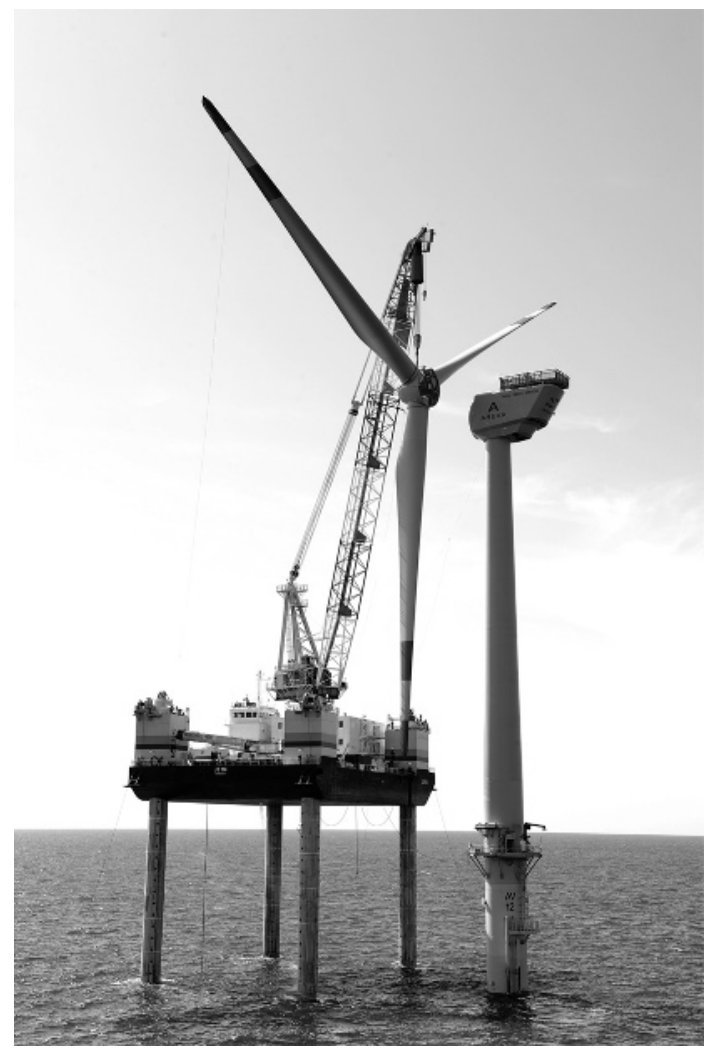

Fig. 2. - Installation of a wind converter of the wind farm alpha ventus (photo: (C) DOTI 2009). 
TABLE I. - Overview of system boundaries.

\begin{tabular}{lllll}
\hline Description & Technical lifetime & $\begin{array}{l}\text { Full load } \\
\text { hours }^{(\mathrm{a})}\end{array}$ & $\begin{array}{l}\text { Maintenance } \\
\text { assignment }^{(\mathrm{b})}\end{array}$ & $\begin{array}{l}\text { Number } \\
\text { of WEC }\end{array}$ \\
\hline alpha ventus & $\begin{array}{l}\text { Foundation and } \\
\text { Submarine Cable }\end{array}$ & $3900 \mathrm{~h} / \mathrm{a}$ & $\begin{array}{l}\text { 10 Helicopter } \\
\text { and 15 Shipping }\end{array}$ & 12 \\
& & $\begin{array}{l}\text { Services per } \\
\text { 20 years }\end{array}$ & & year and WEC \\
& & & \\
& &
\end{tabular}

(a) Including down time and losses during transmission to onshore transformer station.

(b) Maintenance for each wind energy converter (WEC) over the technical lifetime: replacement of 0.5 gearboxes and 1.25 rotor blades.

$\mathbf{2} 2$. Inventory analysis. - In a first step, the inventory - in this case all the component parts and structural elements of the wind farm - was listed. In a second step, the inventory analysis results for the manufacturing phase, the use phase, as well as the disposal phase were built. The main part of the production phase was the calculation of the raw material and their respective masses (under consideration of common proportions of recycled material) and the subsequent processes. Additionally, the transport of the components between the different production facilities and to the building site was included, as well as the assembling of the components (wind energy converters, transformer stations and submarine cables). In conjunction with the operating company, the maintenance and maintenance assignments for the use phase for each wind energy converter were assumed (table I). Part of the disposal phase was the dismantling and the return transports of the structural elements. The inventory analysis result was built in cooperation with respective manufacturers and the operator of the wind farm.

2 3. Impact assessment. - In the next step of the LCA, specific energy expenditures and produced emissions were linked to the inventory analysis result. The database of the Swiss Center for Life Cycle Inventories Ecoinvent [3] lists over 4000 datasets for specific energy expenditures and produced emissions for raw material. Furthermore, data for subsequent processing, like forging or welding, can be withdrawn. With the help of the balancing software $\mathrm{GaBi}[4]$ and the implemented Ecoinvent database, the linking process could be performed and the offshore wind farm analyzed holistically.

\section{Cumulated energy demand}

As the routing indicator the cumulated (primary) energy demand (CED) was chosen, which sums up every energetic input over the life cycle of a product evaluated on a primary energy basis. It is measured in TJ primary energy-equivalent (PE-Eq.). It allows an energetic comparison to other power generating systems and their respective CED.

\section{Global warming potential}

Due to the current public focus on the reduction of greenhouse gases, the global warming potential or greenhouse warming potential cumulates every carbon dioxide equivalent 


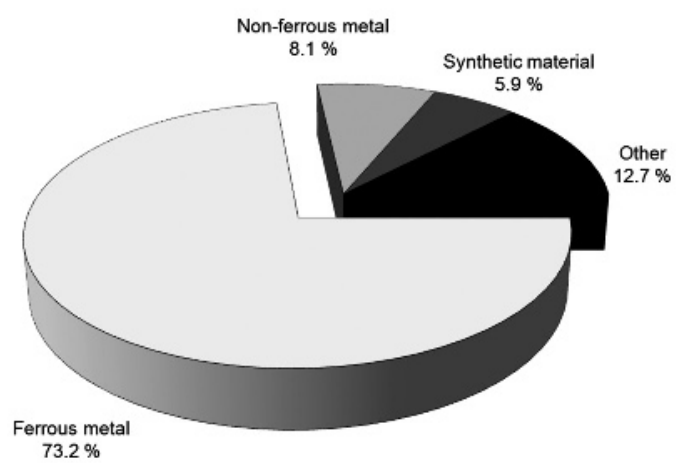

Fig. 3. - Material balance of the wind farm alpha ventus (including the grid connection).

emission. Hence, it describes the anthropogenic global warming effect, which leads to the increase of the global average temperature. It is measured in $\mathrm{kg} \mathrm{CO}_{2}$-Equivalent.

\section{Additional indicators}

In LCAs further indicators, such as the eutrophication potential (EP), the human toxicity potential (HTP), the photochemical ozone creation potential (POCP) and the acidification potential (AP), can be investigated. Depending on the Scope Definition of the LCA, these categories can deliver important results. However, they will not be part of the example described here.

$\mathbf{2} 4$. Interpretation and results. - The results are organized to give an overview of the CED, itemized with respect to the life cycle phases of the wind farm. Table I show all assumptions with respect to the technical lifetime of the foundation and the submarine cable, the full load hours, the maintenance and the maintenance assignments. For the wind farm, fig. 3 displays the total material balance itemizing different substances. All together about 29000 tons of material is installed. Of major significance is the proportion of the ferrous metal $(>73 \%)$. Especially the foundations of the offshore installations, which contribute more than half of the ferrous metal, have a considerable influence. Nonferrous metal has a proportion of about $8 \%$. In the first approximation, the submarine cable adds up to $80 \%$ of the non-ferrous metal.

$C E D$ and GWP results respecting the life cycle phases

In total, about 2300 TJ PE-Eq have to be expended for the entire life cycle of alpha ventus (fig. 4). A proportion of nearly $80 \%$ is attributed to the production phase, followed by the use phase (about 20\%). The disposal phase contains the deconstruction and has a minor influence compared to the other life cycle phases.

Concerning the GWP, about 149000 t $\mathrm{CO}_{2}$-equivalent are expended. The proportions of the different life cycle phases nearly equal the respective one of the CED (fig. 4). This 


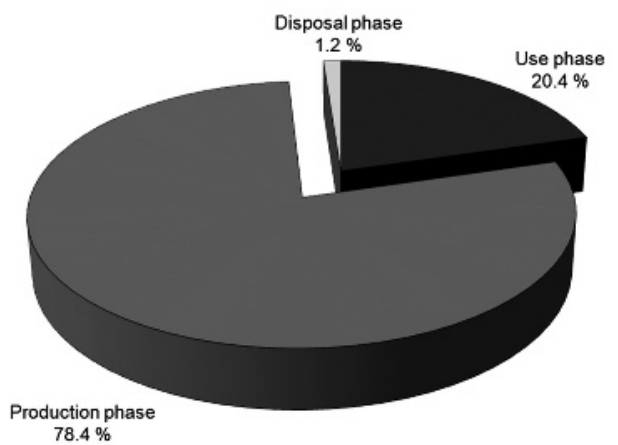

Fig. 4. - CED of the wind farm alpha ventus itemized respecting life cycle phases.

is on account of the high proportion of the $\mathrm{CO}_{2}$ emissions (about 90\%) in the GWP, which are mainly caused by the expenditure of fossil energy. Thus, they are related to the CED. Therefore the following remarks can also give conclusions to those of the GWP.

\section{Production phase}

Different structural components have different influences on the total CED results. The main influence of a single component has the $110 \mathrm{kV}$ submarine cable. Its production contributes about $12 \%$ to the total CED. Due to the high impact of the submarine cable, the distance between the wind farm and the shore is also of major importance. The offshore and onshore transformer stations sum up to 6\%. Each of the 12 converters contributes about $2 \%$ to the CED, the $110 \mathrm{kV}$ submarine cables about $12 \%$ in total. All twelve foundations add up to an amount of $35 \%$ to the total CED.

\section{Use phase}

Investigating the use phase, the calculations show that about $70 \%$ of the 470 TJ PEEq for the use phase (fig. 4) are expended for shipping services (table I). Another 12\% are expended for transports by helicopters. Changing gear boxes, blades and oil as well as the transport and assembling of the spare parts have a proportion of about $18 \%$ altogether.

\section{3. - Payback time}

The energetic payback time (fig. 5) is an important key figure to determine the sustainability of power plants using renewable energies. It describes the time frame to compensate the energetic expenses, valued as primary energy, for the entire life cycle of the power plant. In this case, the offshore wind farm generates electricity without any additional energetic input to compensate the energetic expenses for production, use and disposal. To value the generated electricity as primary energy, Germany's electricity mix 


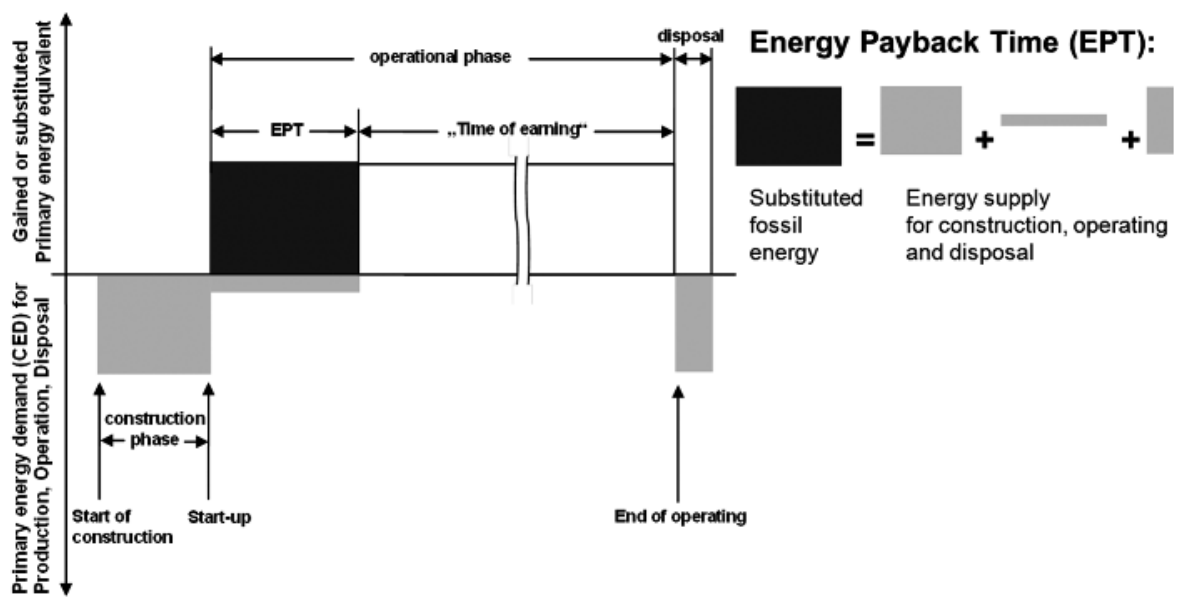

Fig. 5. - Energy payback time.

was chosen as the comparing system. The calculations are based on the computational method of VDI 4661 [5].

To investigate the influence on the climate change, the greenhouse gas payback period was calculated, too. This key figure describes the time for the compensation of the carbon dioxide equivalent emissions during the entire life cycle. Again, as the comparing system, the German electricity mix was chosen.

The results show that the energetic input for the wind farm is amortized after less than 10 months (table II). The greenhouse gas payback period is about a half month longer than the energetic payback period. The results show a strong correlation between each other. Due to the effect that the $\mathrm{CO}_{2}$ emissions are mainly based on the energetic expenditures, the high proportion of about $90 \%$ of the $\mathrm{CO}_{2}$ emissions in the emitted greenhouse gases lead to this correlation. Therefore, within less than one year the energetic expenditure as well as the greenhouse gas emission of the entire life cycle of alpha ventus is amortized.

More results of further sensitivity calculations are published in [6].

TABLE II. - Energetic and greenhouse gas payback period.

\begin{tabular}{llll}
\hline Description & $\begin{array}{l}\text { Generated electricity } \\
\text { over 20 years }\end{array}$ & $\begin{array}{l}\text { Energetic payback } \\
\text { period }^{(\mathrm{b})}\end{array}$ & $\begin{array}{l}\text { Greenhouse gas } \\
\text { payback period }^{(\mathrm{c})}\end{array}$ \\
\hline $\begin{array}{l}\text { alpha ventus } \\
(60 \mathrm{MW})\end{array}$ & $4680 \mathrm{GWh}$ & $8.8 \mathrm{Month}$ & 9.1 Month \\
\hline
\end{tabular}

\footnotetext{
(a) Unwaighted = secondary energy.

(b) Energetic supply factor for the German electricity mix at the high-voltage grid: $3.007 \mathrm{kWh}$ PE-Eq. $/ \mathrm{kWhel}$.

(c) Greenhouse gas supply factor for the German electricity mix at the high-voltage grid: $0.665 \mathrm{~kg} \mathrm{CO}_{2}$ Eq./kWhel.
} 


\section{REFERENCES}

[1] German Standard DIN-EN-ISO-14040 (2006). Environmental management - Life cycle assessment - Principles and framework (ISO 14040:2006), BeuthVerlag, Berlin.

[2] German Standard DIN-EN-ISO-14044 (2006). Environmental management - Life cycle assessment - Requirements and guidelines (ISO 14044:2006), Beuth Verlag, Berlin.

[3] Ecoinvent database, Version 2.01 (2007). Implemented in Gabi 4.3, Swiss Centre for Life Cycle Inventorie, LBP University Stuttgart and PE INTERNATIONAL GmbH.

[4] GaBi V. 4.3 software and database for life cycle assessments (2007). LBP University Stuttgart and PE INTERNATIONAL GmbH.

[5] Association of German Engineers (Editor), Energetic characteristics, Definitionterms-methodology, VDI-guideline 4661 (2003).

[6] Wagner H-J., BaAck C., Eickelkamp T., Epe A., Lohmann J., Troy S. et al., Life Cycle assessment of the offshore wind farm alpha ventus, Energy, 36 (2011) 2459. 